\title{
Utilization of Social Media Platforms among Information Science Students at University of Kabianga
}

\author{
Geoffrey Maweu1, Omondi Aguok Yudah² \\ ${ }^{1}$ School of Information Science and Knowledge Management, Department of Publishing, Media \& IT, University of Kabianga, \\ Kericho, Kenya \\ ${ }^{2}$ School of Information Science and Knowledge Management, Department of Information Science \& Technology University of \\ Kabianga, Kericho, Kenya \\ Email: yudez82@gmail.com
}

How to cite this paper: Maweu, G. and Yudah, O.A. (2020) Utilization of Social Media Platforms among Information Science Students at University of Kabianga. Open Access Library Journal, 7: e6090.

https://doi.org/10.4236/oalib.1106090

Received: January 19, 2020

Accepted: March 13, 2020

Published: March 16, 2020

Copyright () 2020 by author(s) and Open Access Library Inc.

This work is licensed under the Creative Commons Attribution International License (CC BY 4.0).

http://creativecommons.org/licenses/by/4.0/

\begin{abstract}
Social media has rapidly revolutionized the information and communication domain in the world. The applicability of social media in the academic sphere is occasioned by prospects and challenges. Consequently, it has created a bone of contention within the academic realm. The study therefore reviewed social media applications and their preferential utilization by university students in knowledge sharing. This study seeks to address the research problem; the university management has endeavored in connecting the institutions with the outside world through developing information communication and technological (ICT) infrastructures. However, little is known on how students use new media technologies for academic purposes. The study adopted a descriptive research design, where closed-ended questionnaires were distributed to the respondents. The respondents comprised of 103 students in the University of Kabianga, school of information science and knowledge management. The research revealed that students use social media majorly for entertainment purposes. Subsequently, it realized that the new media affect university students both positively and negatively but without authentic studies locally. It is hoped that this study will shade more light than darkness into the application of new media formats in learning at Kenyan universities. This will open new avenues of knowledge sharing and networking for maximum utilization of mined and captured information within the academic corridors.
\end{abstract}

\section{Subject Areas}

Information Science 


\section{Keywords}

Social Media, New Media, University Students, Knowledge Sharing

\section{Introduction}

Social media platforms are preferred by university students as a means for knowledge sharing. This is due to their features and capabilities that encourage, support and enable people to share knowledge easily and effectively through different mechanisms. Universities generate Knowledge diversely at different levels, ranging from individual projects, group discussions, brain storming sessions and research undertakings. Once the generated knowledge has been captured for whatever purposes, it remains to be shared and disseminated within and without university realm. Scholars and practitioners widely recognize knowledge as critical asset for individuals as well as organizations' success in the increasingly competitive environment [1]. It is common knowledge that people are the best means of getting meta-knowledge about our search target and capabilities. For instance, talking to each other provides a highly valuable learning activity that is primarily a tacit-tacit knowledge transfer, which is knowledge that resides in people or expert minds (Artificial Intelligence). New invention of technology offers a new medium through which individuals that share similar interests, problems and responsibilities can share knowledge. Social media is the possibility of people to create their own content and to easily be able to share the content [2]. This content is not imposed by others or by rules, people are free to pursue their own needs. This ensures that the information or knowledge that is shared really comes from the self, and that it can be expressed the way it was actually meant.

\subsection{Statement of the Problem}

Social media platforms are increasingly playing a key role in the techno savvy population's lives. This is by allowing people to interact and communicate across the world including in Kenya. In recent times, institution of high learning has adopted social media as a mode of delivery, a tool for learning and a communication channel between lecturers, students, management staff, researchers and other key stakeholders. This has seen the developments of Knowledge mining, organization and sharing grow into systems as well as reliance on group resources alongside other mechanisms for the improvement of students, lecture deliveries and management of varsities. The usage of social media in learning offers students with the capability to get more value added information, to connect with others, which makes academic knowledge sharing in education convenient. Social media tools in the academia community give students, lecturers, managers among others with a wide range of possibilities in the improvement of learning methods. Through the networks, it becomes possible to share and interact remotely. Students also make use of online tutorials as additional 
knowledge resources that are shared through the social platforms.

However, despite the enormous efforts by the university management in developing information communication and technological (ICT) infrastructures, little is known on how students use new media technologies for academic purposes. In view of the fore going, the study examines the application and use of new media platforms on knowledge sharing together with the arising challenges in the University of Kabianga, School of Information Science and Knowledge Management.

\section{Purpose of the Study}

This study aims at assessing the application of new media platforms on knowledge sharing in university of Kabianga, specifically by exploring the use of social media in lecture halls by both the lecturers and students, with an intention of developing the best practice of academic knowledge sharing and encouraging linkages and knowledge networking.

\subsection{Significance of the Study}

The study will shade light on the best practices for the use of social media in university education as a form of knowledge sharing avenue. This understanding will guide the proper usage hence influencing the learning environment to the advantage of the students, lecturers, researchers and other stakeholders in the varsity communities.

\section{Literature Review}

The use of new media applications has been rising rapidly during last few years and as Patil asserts, it is not only being used by the working people but also there is heavy increase in the use of social media by the students or education society [3]. A 2015 survey conducted in Zambia, established that 71\% of Zambians use internet on almost a daily basis with $63 \%$ of them being university students [4]. And while there are no corresponding statistics regarding the use of Internet by Kenyan university students, it is safe to conclude that its use is widespread within the corridors of Kenyan institutions of higher education both by the students and their lecturers. It's positive or negative effects notwithstanding; various studies have conclusively established that the use of social media by university students and in the education sector in knowledge sharing is widespread and acceptable if not almost mandatory.

\subsection{Application of New Media in Knowledge Sharing, Teaching and Learning}

The use of new media in knowledge generated resource sharing within universities cannot be over-emphasized. The question thus is the extent of its adoption by the university community and how they use it. Is it for academic purposes or leisure? Similarly, how do lecturers use social media in engaging with their students? Is the line between educational use and other leisurely activities thin or 
blurred among the teaching staff of varsities and their students? Also, what are the negative and positive impacts of social media use in resource sharing within the education sector? [5] suggested that social media might be very useful when it comes to academic issues, i.e. discussion boards among classmates and Facebook page for school programs. However, an opposite finding revealed by [6], showed that social media has negative effects on the students' academic performance. The students' proficiencies and grades were affected through use of social media. With studies giving conflicting conclusions, where will sanity be found or is it a lost case?

\subsection{Social Media Usage in Knowledge Management by University Students}

As indicated in the above section, various studies have unanimously agreed that university students are notorious when it comes to usage of social media, be it for educational purposes or otherwise. Additionally, studies have made conflicting conclusions in regard to the impact of social media usage by varsity students with some indicating it has positive impacts while others disagree. There are no studies or concrete statistics on the same in the Kenyan universities, but the truth cannot be far from the conclusions of these studies. Thus the existence of numerous Facebook pages and groups, WhatsApp groups and telegram channels owned by university students and discussing university issues, educational and otherwise attest to the fact that usage of new media is not alien to academic community. Sheer observation will tell you that almost everyone at the university owns or at least use a smartphone (technologically referred to us palmtops), gadgets which have the ability to carry new media platforms and programs.

\section{Methodology}

The research adopted a descriptive survey research design. Closed ended questionnaire was used to collect data from the respondents. The respondents comprised of 103 students in the University of Kabianga, school of information science and knowledge management. This population was selected because it was convenient. The data collected from the field was complemented by secondary data from books and journals, which are found online via google scholar, and Emerald, among other websites.

\section{Findings}

\subsection{Forms of Social Media Used by Students}

Figure 1 below shows that the devices used in accessing social media forms. It that $17(34.0 \%)$ responded used smartphone/DPA, 1 (2.0\%) indicated laptop/computer, and $32(64.0 \%)$ students responded by smartphone the use of both devices. The researcher deduced that the majority of the responded preferred using dual-devices and then followed by (34.0\%) responses indicating the use of smartphone devices in accessing social media forms. Similarly, most 


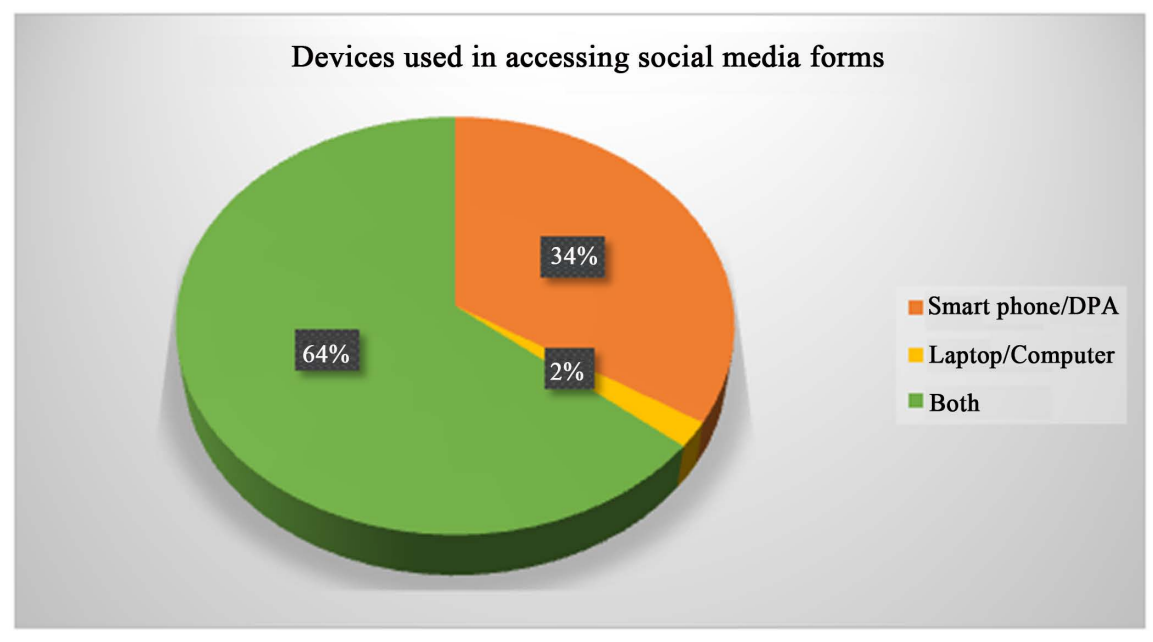

Figure 1. Devices used in accessing social media.

students could afford Laptops and computer systems and, therefore, would alternatively resort to the smartphone as the preferred device in accessing social media.

Having acknowledged the common usage of smart phones by the respondents, the researcher sought to establish the form of social media adopted. Figure 2 below shows the distribution of various forms of social media in smartphones. Figure 2 shows forms of social media in social media, where Facebook had 39 (22.8\%), Twitter 27 (15.8\%), Instagram 25 (14.6\%), WhatsApp 45 (26.3\%), You Tube 30 (17.5\%) and Snapchat 5 (2.9\%) respondents. The high frequency of each form of social media was as a result of having choice of selection of more than one form.

\subsection{Usage of Social Media in Academia}

The research sought to understand the forms and means of social media usage in academia. It was established that a significant majority of the respondents, 46 (94\%) indicated that they use social media in sharing academic content. Consequently, the small insignificant portion of the respondents, $4(6 \%)$, suggested that they don't use social media in scholarly knowledge sharing. The overwhelming use of social media is occasioned by the well-established technological wire-less internet connection within the campus, and above all, most students are tech-savvy.

An in-depth analysis of the forms of the platforms used by the respondents revealed that majority, $45(69.2 \%)$ used WhatsApp as a conventional means of knowledge sharing, followed by Facebook 8 (12.3\%). Other forms included You Tube 6 (9.2\%), twitter 4 (6.2\%), and Instagram and LinkedIn trailing with a minute $1(1.5 \%)$. Students highly prefer WhatsApp because of its flexibility and ability to create group communication, thus facilitating mass interaction. Therefore, most respondents who have smartphones are members of WhatsApp a group. On the contrary, LinkedIn and Instagram surprisingly attracted the 


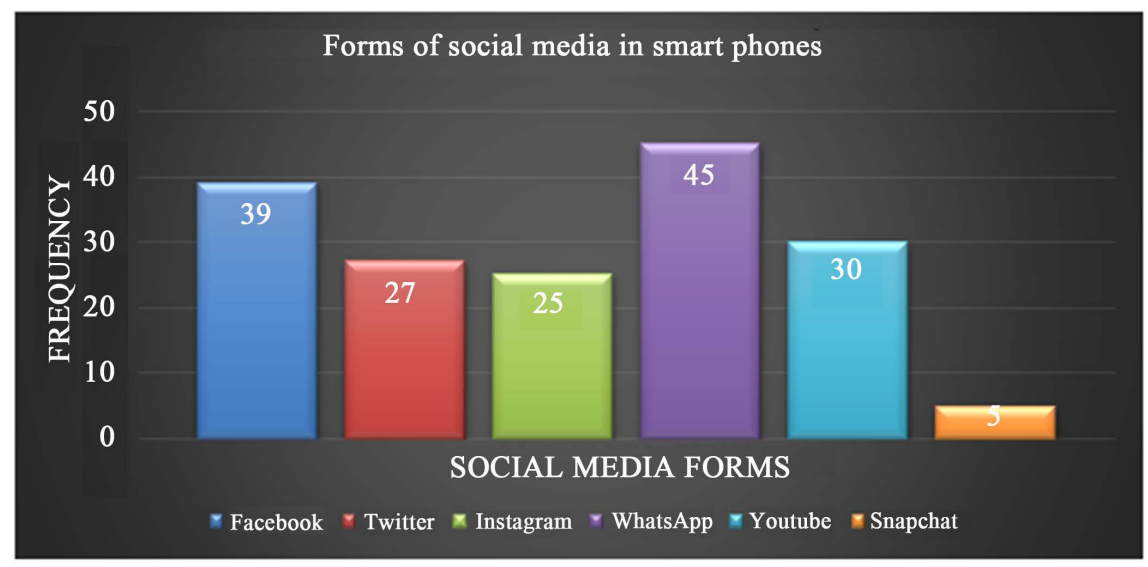

Figure 2. Forms of social media in smart phones.

smallest possible number of respondents. The small numbers are attributed to fact that LinkedIn is majorly used for professional linkages while twitter is usually followed opinion leaders, and most respondents are not interested in following opinion leaders or professionals' (Figure 3).

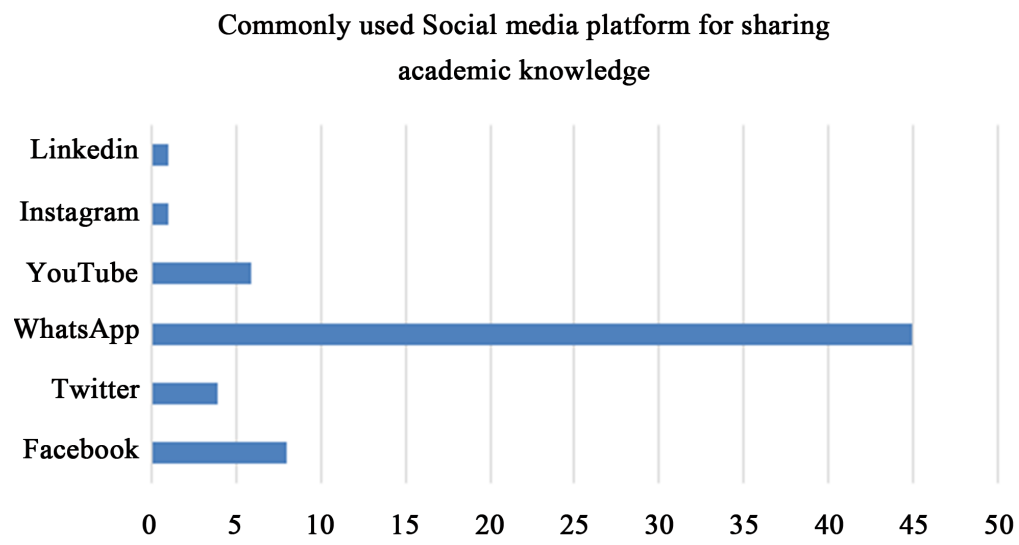

Figure 3. Social media platforms.

\subsection{Factors Affecting Academic Knowledge Sharing}

The researcher sought to determine the factors influencing the use of social media in sharing academic knowledge. It was revealed from the table that the respondents are driven by self-motivation 27 (54.0\%), followed by organizational culture $13(26.0 \%)$ and finally enjoying helping others 10 (20.0\%). Majority of the respondents indicated that self-motivation pays a significant role in knowledge sharing. This high number of respondents is attributed to the personal conviction and the collective urge of sharing knowledge through group discussions and assignments (Figure 4).

\subsection{Factors Hinders Sharing Academic Knowledge through Social Media}

Figure 5 illustrated on the factors that hinder students from sharing academic 


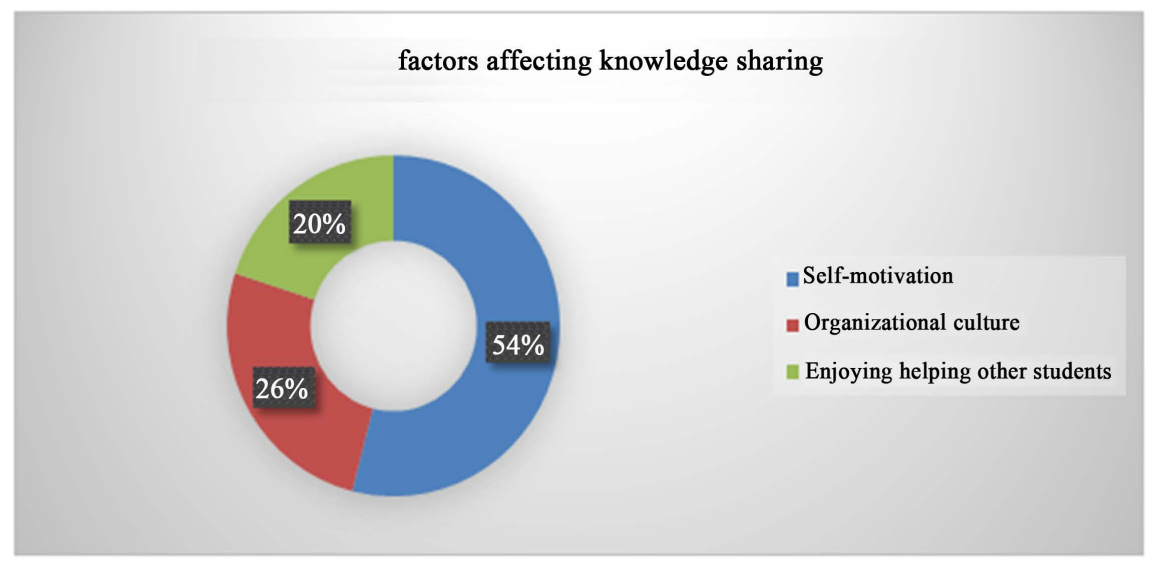

Figure 4. Factors affecting knowledge sharing.

Factors hinders sharing academic knowledge through social media

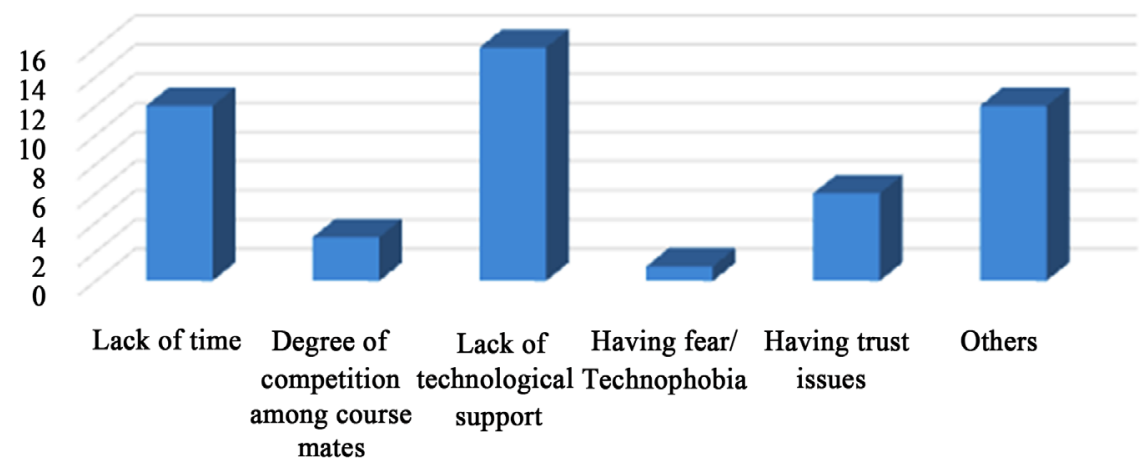

Figure 5. Factors hindering academic knowledge sharing.

knowledge through social media. Majority of the respondents $16(32.0 \%)$ saw lack of technological support as the major hindrances, while 12 (24.0\%) blamed it on lack of time, $12(24.0 \%)$ saw others factors, $6(12.0 \%)$ were trust issues, 3 (6.0\%) saw degree of competition among course mates and finally $1(2.0 \%)$ was having fear/technophobia. This clearly reveals that those who do not share academic knowledge claimed lack of technological support as the major hindrances.

\section{Discussions of the Findings}

\subsection{Types of Social Media}

Major development of Web applications during the last decade, termed as Web 2.0 , is the emergence and intensive use of social networking sites (SNS). Examples of SNS are Myspace, Facebook, LinkedIn, Twitter, Flicker, Instagram, and WhatsApp. Tango, Line, Yahoo, Hike, We Chat, Skype, Imo, BBM, Viber etc. [7]. Social media users create, share and/or exchange information and ideas in virtual communities and they are able to network with other members who share similar or common interest, dreams and goals [8]. 


\subsection{Popularity of Social Media Sites among the Varsity Students}

Just like the evolution of the higher education system in Kenya and globally, the new media has also greatly changed at an even higher pace. New social media platforms have killed the old ones. WhatsApp for instance rendered BBM obsolete, while the secure and secretive nature of Telegram has left snapchat and 2go redundant. There are social media platforms that are more popular than others among the university students and within the general populace.

Studies on the preferred social media platform have established that WhatsApp remains the most popular social media application. A Ghanaian study found that the majority of students used WhatsApp as the most widely used social media platform followed by Facebook and Twitter [9]. While students use social media in other leisurely and formal activities, within the context of education, students mainly use the new media for communication with lecturers according to.

\subsection{Knowledge Sharing in Teaching and Learning through Social Media}

According to [10] social network sites have attracted considerable attention among scholars and educators due to the increasing popularity among students and the potential effect on academic performance.

Hypothetically, there are many ways in which social media can be used in teaching and learning at the university. This includes communication, information sharing (remotely-that is away from class—and in class), video conferencing, projecting on the wall, research and actual learning itself. However, [8] avers that the new media is predominantly used only to communication between the classmates, fellow students and also with lecturers.

Social media are mostly used by students to communicate and exchange ideas with lecturers specifically in western contexts.

At the University of Kabianga, it is widely acceptable and public knowledge that students share information regarding learning and other corresponding tasks amongst themselves, while lecturers send reading materials and assignments to students through social media platforms such as gmail's hangout among others. This in essence promotes knowledge organization, retrieval and sharing within the university academic community. Students also submit assignments and communications to the lecturers through the same.

Students in similar common units have been known to form WhatsApp groups where they invite their lecturers and use the platform to share and discuss purely academic knowledge related issues by information request and sharing regarding the said unit.

\subsection{Adoption of Social Media Platforms by Students}

A 2015 study in Zambia, as mentioned in the introduction, indicated that $63 \%$ of social media users in the country are in the university sector. A recent study by 
USIU indicated that most Kenyans aged between 23 and 35-university students fall under this age bracket-spend an average of three hours per day on social media. Another report released in the year 2017/2018 by Communications Authority of Kenya (CAK) indicated that 40.7 million people bought data bundles in that year, with $70 \%$ of them being youths.

The fact that virtually every student at the University of Kabianga owns a Smartphone attests to the high probability that they use social media in learning purposes. While adoption of social media within the university circle is not purely for learning purposes, [11] pointed out how an increased use of Social Media in higher education would lead to reconnecting academic institutions to the new generations of students. While the existence of various groups and web pages used by the students and official twitter and Facebook university pages (University of Kabianga included)... "Provides empirical evidence relating to their use by students in higher education" [12].

In addition, the outcomes of a survey performed by [13] showed that lecturers and students differ somewhat in their current and anticipated uses of social media such as Facebook. It was noted that there is a significant difference between the perceived role of this tool as social, rather than educational. Students look like much more open to the idea of using Facebook instructionally than do lecturers.

\subsection{Positive and Negative Impacts New Media Platforms in Knowledge Sharing}

The existence of various studies with conflicting conclusions on the impacts of social media usage by university students points to the fact that it has both positive and negative effects on students' learning, professional and personal lives. Sudha and Kavitha (2016) believe that social network sites have attracted considerable attention among scholars and educators due to the increasing popularity among students and the potential effect on academic performance. Equally [14], for instance, contend that social networking have a meaningful effect on the students' academic performances. Conversely, Mingle and Adams (2015) observed that there are some students experienced improvement in their reading skills as a consequence of participation and involving social media. Also, respondents shared ideas, discussed and shared examination questions among themselves on social media.

[15] argued that the development of technology and increase in internet usage, social media has become a part of our daily lives. If social media is used in a positive way, it can help students and youth to get knowledge that can be used to improve their academic performances. On his part, [16] alleged that the use of social media can be a good outlet to deal with academic frustrations, especially if the students are in contact with another student that is having the same problem. Social media lets students to get connected with other students, which can be very useful because it will allow them to discuss class matters via social media. Additionally, Menseh and Nizam also warns against the abnormal use of social 
media platforms by students and suggested it is useful that universities and colleges in Malaysia educate their students to use these platforms positively for educational purposes which will ultimately result in a positive impact on their academic performance.

Moreover, Heffner Tara conducted a study among undergraduates at Rowan University of the USA. The study results described that social media do not have a positive effect on the students' academic achievements. Because the student GPA decreased as much as they were engaged in social media, the study suggested the undergraduate students should manage and monitor their time spent using social media such as Facebook. In another study, [17] discovered social media as a factor in the lacking of habits of reading newspapers among students and it may cause them to lose much advantageous information consisted of the newspaper.

At the University of Kabianga, there are positive effects of social media usage namely: students are easily able to share information and resources amongst themselves and also with lecturers, research, co-curricular activities organization, departmental; institutional and class updates are easily received and shared through social media platforms while distance learning and private students frequently communicate with their tutors through social media. On the contrary, students are easily addicted to social media there distracting there reading habits and as Mushtaq (2015) ascertains, social media addiction may lead to poor reading habits thus deserting important information hubs such as newspapers and static libraries among others.

\section{Conclusions}

Based on the studies, we have quoted we can safely conclude that positive effects of social media far outweigh the negative effects. It is therefore in order to state that social media is a useful tool in teaching and learning at the university of Kabianga as well as other high education institutions and can become an even more powerful and effective learning/communication tool if implemented and regulated properly.

It can therefore be recommended that the teaching staff and other social media users such as bloggers and Facebook page owners, disseminate advantageous agendas which will help students in enhancing their knowledge repositories and information reserves.

\section{Conflicts of Interest}

The authors declare no conflicts of interest regarding the publication of this paper.

\section{References}

[1] Yang, J. (2007) The Impact of Knowledge Sharing on Organizational Learning and Effectiveness. Journal of Knowledge Management, 11, 83-90.

https://doi.org/10.1108/13673270710738933 
[2] Kietzmann, J., Hermkens, K., McCarthy, I. and Silvestre, B. (2011) Social Media? Get Serious! Understanding the Functional Building Blocks of Social Media. Business Horizons, 54, 241-251. https://doi.org/10.1016/j.bushor.2011.01.005

[3] Vishranti, R. and Prafulla, P. (2016) Use of Social Media in Education: Positive and Negative Impact on the Students. International Journal on Recent and Innovation Trends in Computing and Communication, 4, 281-285.

[4] ICTA, CSO, Republic of Zambia Ministry of Transport and Communications (2015) ICT Survey Report-Households and Individuals. Lusaka.

[5] Heffner, T. (2016) The Effects of Social Media Use in Undergraduate Students. Rowan University, Technology and Management ICAIM.

[6] Wang, Q., Chen, W. and Liang, Y. (2011) The Effects of Social Media on College Students. Johnson \& Wales University, Providence, RI.

[7] Mustafa, I.M. and Al-Jabri, I.M. (2016) Social Networking, Knowledge Sharing, and Student Learning: The Case of University Students. Computers \& Education, 99, 14-27. https://doi.org/10.1016/j.compedu.2016.04.007

[8] Sharma, A. and Shukla, A.K. (2016) Impact of Social Messengers Especially WhatsApp on Youth: A Sociological Study. International Journal of Advance Research and Innovative Ideas in Education, 2, 367-375.

[9] Mingle, J. and Adams, M. (2015) Social Media Network Participation and Academic Performance in Senior High Schools in Ghana. Library Philosophy and Practice (E-Journal), p. 1286.

[10] Sudha, S. and Kavitha, E. (2016) The Effect of Social Networking on Students' Academic Performance: The Perspective of Faculty Members of Periyar University, Salem. Library Philosophy and Practice (e-Journal), 1455.

[11] Junco, R. (2015) Student Class Standing, Facebook Use, and Academic Performance. Journal of Applied Developmental Psychology, 36, 18-29. https://doi.org/10.1016/j.appdev.2014.11.001

[12] Cooke, N.J. (2015) Team Cognition as Interaction. Journal of Current Directions in Psychological Science, 24, 415-419. https://doi.org/10.1177/0963721415602474

[13] Roblyer, M.D., McDaniel, M., Webb, M., Herman, J. and Witty, J.V. (2010) Findings on Facebook in Higher Education: A Comparison of College Faculty and Student Uses and Perceptions of Social Networking Sites. The Internet and Higher Education, 13, 134-140. https://doi.org/10.1016/j.iheduc.2010.03.002

[14] Menseh, SO. and Nizam, S. (2016) The Impact of Social Media on Students' Academic Performance: A Case of Malaysia Tertiary Institution. International Journal of Education, Learning and Training, 1, 14-21. https://doi.org/10.24924/ijelt/2016.11/v1.iss1/14.21

[15] Hasnain, H., Nasreen, A. and Ijaz, H. (2015) Impact of Social Media Usage on Academic Performance of University Students.

[16] Heffner, T. (2016) The Effects of Social Media Use in Undergraduate Students. Theses and Dissertations, 1440. https://rdw.rowan.edu/etd/1440

[17] Mushtaq, I. and Khan, S.N. (2012) Factors Affecting Students' Academic Performance. Global Journal of Management and Business Research, 12, 17-22. https://globaljournals.org/GJMBR_Volume12/3-Factors-Affecting-Students-Acade mic.pdf 